\title{
Molecular analysis of CFTR gene mutations among Iraqi cystic fibrosis patients
}

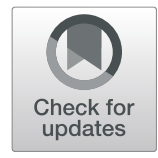

Asal Gailan Abdul-Qadir ${ }^{1}$, Bassam Musa Al-Musawi ${ }^{2^{*}}$, Rabab Farhan Thejeal ${ }^{3,4}$ and Saad Abdul-Baqi Al-Omar ${ }^{5}$

\begin{abstract}
Background: Cystic fibrosis (CF) is an autosomal recessive multisystem disease that results from mutation(s) of the cystic fibrosis transmembrane conductance regulator (CFTR) gene. More than 2100 mutations and polymorphisms have been reported in this gene so far. Incidence and genotyping of CF are under-identified in Iraq. This study aims to determine the types and frequencies of certain CFTR mutations among a sample of Iraqi CF patients. Two groups of patients were included: 31 clinically confirmed CF patients in addition to 47 clinically suspected patients of CF. All confirmed patients had typical, moderate-severe clinical presentation and course of the disease. Molecular analysis was performed on the majority of enrolled patients using the CF-stripAssay ${ }^{\circledR}$ kit supplied by ViennaLab diagnostics, GmbH, Austria.

Results: The mutation-detection rate from the tested 34 mutations in this study was $19.5 \%$ and the 8 detected mutations were as follows: $3120+1 \mathrm{G}>\mathrm{A}$ and W1282X were found in $3(4.17 \%)$ patients each; F508del and R1162X were found in 2 (2.78\%) patients each; 3272-26A>G, R347P, 1507del, and 2183AA>G were found in 1 (1.38\%) patient each. Polymorphic variants of IVS8, namely $5 \mathrm{~T}, 7 \mathrm{~T}$, and $9 \mathrm{~T}$, were detected in $\sim 70 \%$. These results were nearly similar to what was reported in regional countries.

Conclusion: Cystic fibrosis seems to be not rare as previously thought. 3120+1G>A and W1282X are the two most commonly detected mutations. F508del needs to be included in all future tests, while the 1507del mutation was uniquely reported in this study but not in regional studies.
\end{abstract}

Keywords: Cystic fibrosis, CFTR, Mutations, 3120+1G>a, W1282X, F508del, Iraq

\section{Background}

Cystic fibrosis (CF; MIM \#219700) is an inherited autosomal recessive disorder with multisystem manifestations [1]. It is estimated to affect as many as 1 in 20003000 Caucasian newborns in Europe and USA [2] and 1 in 2560 to 1 in 15,876 in the Middle East. The incidence differs concerning the ethnic and geographic background as well as the degree of consanguinity [3].

$\mathrm{CF}$ is caused by mutations of the cystic fibrosis transmembrane conductance regulator (CFTR) gene that spans about $250 \mathrm{~kb}$ of genomic DNA; it is located at

\footnotetext{
* Correspondence: abmsadik@yahoo.com; bm.al-

musawi@comed.uobaghdad.edu.iq

2Department of Pathology and Forensic Medicine, College of Medicine,

University of Baghdad, Baghdad, Iraq

Full list of author information is available at the end of the article
}

chromosomal region 7q31.2 and contains 27 exons. More than 2100 CFTR mutations and polymorphisms have been detected to date, with variable frequencies [4].

Generally, mutations associated with clinical manifestations are grouped into six main classes depending on how they affect protein structure and function. Mutation class I-III are considered severe mutations, while class IV-VI mutations are considered less severe ones [5].

The major manifestations of the disease involve mainly the respiratory and gastrointestinal (GI) systems (chronic productive cough, dyspnea, recurrent lower respiratory tract infections, pancreatic insufficiency, malabsorption, fatty diarrhea, and distal intestinal obstruction syndrome). In children, meconium ileus and failure to thrive are additional manifestations. Other features can also be present like kidney and endocrine gland 
involvements in addition to infertility in both males and females [6].

Diagnosis depends on the patient's suggestive clinical presentation, or positive newborn screening test (elevated immunoreactive trypsinogen level in blood) plus laboratory evidence of CFTR dysfunction like two positive sweat chloride tests $(>60 \mathrm{mmol} / \mathrm{L}$ of chloride in sweat) obtained on separate days or identifications of two CFTR mutations or abnormal nasal potential difference [1].

CFTR molecular genetic testing is important for the diagnosis especially for inconclusive clinical/biochemical results and in prenatal diagnosis. Direct gene analysis relies on either testing for the presence or absence of known mutations, which can be achieved by a panel test, or scanning the samples for any deviation from the wild sequence (for unknown mutations) using sequencing methods [7].

$\mathrm{CF}$ has largely been under-diagnosed in Iraq due to a low index of suspicion and inadequate facilities for diagnosis in some regions. To the best of our knowledge, no published data are available on the incidence of CF in Iraq.

This investigation aims to detect the types and frequencies of certain CFTR mutations among a group of clinically diagnosed Iraqi cystic fibrosis children.

\section{Methods}

In this cross-sectional study, two groups of Iraqi Arab CF patients were recruited. The first group included clinically confirmed patients of CF [suggestive clinical features and biochemical abnormalities, plus positive sweat chloride test $(>60 \mathrm{mmol} / \mathrm{L})]$. They were recruited mostly from the Gastroenterology and Liver Diseases Outpatient Clinic, Children Welfare Hospital, Baghdad, Iraq. They attended this tertiary center from all over the country, but mostly from Baghdad. Molecular analysis was performed on the majority of them using CFstripAssay $^{\circ}$ kit supplied by ViennaLab diagnostics, $\mathrm{GmbH}$, Austria. The assay covers 34 mutations and 3 polymorphic variants in the CFTR gene allocated on 2 strips. These mutations are CFTRdel2, $3(21 \mathrm{~kb})$, I507del, F508del, 1717-1G>A, G542X, G551D, R553X, R560T, 2143delT, 2183AA>G, 2184delA, 2184insA, 2789+5G>A, R1162X, 3659delC, 3905insT, W1282X, N1303K, G85E, 394delTT, R117H, Y122X, 621+1G>T, 711+1G>T, 1078delT, R334W, R347H, R347P, A455E, $1898+1 \mathrm{G}>\mathrm{A}, 3120+1 \mathrm{G}>\mathrm{A}, 3272-26 \mathrm{~A}>\mathrm{G}, \mathrm{Y1092X}, 3849+$ $10 \mathrm{kbC}>\mathrm{T}$, in addition to 3 polymorphisms, namely IVS8 5T, 7T, and 9T "1201-12T[n] $(n=5 / 7 / 9)$ ".

The second group included clinically suspected patients of CF; all reside in Basra City in the South of Iraq and were referred to a genetic laboratory for genetic testing using the same kit. Their clinical features and biochemical findings were not available; besides, the sweat chloride test was not available in that city and thus was not performed. They were included in this study for the sake of collecting all available molecular data of $\mathrm{CF}$ in Iraqi patients. The total number of enrolled patients was, therefore, 72 from the two groups.

Molecular diagnosis included DNA extraction from peripheral blood samples, multiplex PCR amplification using biotinylated specific primers, followed by hybridization of amplification products to test strips containing allele-specific oligonucleotide probes immobilized as an array of parallel lines. The bound biotinylated sequences are detected using streptavidin-alkaline phosphatase and color substrates.

Verbal consents were taken from the patients' parents and the study was approved by the Research Ethics Committee, Dept. of Pathology and Forensic Medicine, College of Medicine, University of Baghdad (document \#1356 on October $23^{\text {rd }}, 2019$ ) as well as from the Ethical Committee of the Ministry of Health, Baghdad, Iraq (document \#45961 in November $25^{\text {th }}, 2019$ ).

\section{Results}

The current study recruited two groups of patients. The first group included 31 previously diagnosed CF patients; their ages ranged between 3 months and 15 years (mean $\pm \mathrm{SD}=4.6 \pm 4.02)$ years; $18(58.06 \%)$ of them were males and $13(41.94 \%)$ were females (M:F ratio of 1.38 : 1). Most [27/31 (87.1\%)] patients were products of consanguineous marriages; 5/31 (16.13\%) patients had a positive family history of $\mathrm{CF}$.

The majority [16 (51.62\%)] of patients presented during the first year. The most frequent clinical presentation was typical (combined pulmonary and GI manifestations) (chronic cough with dyspnea, recurrent lower respiratory tract infection, and greasy stool) as seen in 27 (87.1\%) patients (Tables 1 and 2).

All patients included in this group had a sweat chloride value ranging between ( 61 and $132 \mathrm{mmol} / \mathrm{L}$ ) with a mean \pm SD of $97.13 \pm 21.51 \mathrm{mmol} / \mathrm{L} ; 18$ (58.1\%) patients had elevated liver enzymes (ALT, AST, and ALP); 13 (41.9\%) had elevated total serum bilirubin, while 12 (38.7\%) patients had a low total serum protein. Sputum culture revealed Pseudomonas aeruginosa in 6 (19.3\%) patients and Klebsiella spp. in $2(6.5 \%)$ patients; 26 (83.9\%) patients had steatorrhea (Table 3).

Complications encountered throughout the course of the disease are summarized in Table 4.

Molecular analysis was performed on 25 CF patients in this group; the remaining 6 patients either died before blood aspiration or could not attend due to COVID-19 lockdown. Results revealed the presence of 3 mutations in $5 / 25(20 \%)$ patients and the presence of IVS8 
Table 1 Basic demographic and clinical features of 31 Iraqi CF patients

\begin{tabular}{|c|c|c|}
\hline Variables & Variables & No. (\%) \\
\hline \multirow[t]{2}{*}{ Gender } & Male & $18(58.06 \%)$ \\
\hline & Female & $13(41.94 \%)$ \\
\hline \multirow[t]{2}{*}{ Consanguinity } & Positive & $27(87.1 \%)$ \\
\hline & Negative & $4(12.9 \%)$ \\
\hline \multirow[t]{2}{*}{ Family history } & Positive & $5(16.13 \%)$ \\
\hline & Negative & $26(83.87 \%)$ \\
\hline \multirow[t]{3}{*}{ Residence in Iraq } & North & $1(3.2 \%)$ \\
\hline & Middle & $26(83.9 \%)$ \\
\hline & South & $4(12.9)$ \\
\hline \multirow[t]{2}{*}{ Clinical picture } & Typical manifestations & $27(87.1 \%)$ \\
\hline & Atypical (one system) manifestations & $4(9.68 \%)$ \\
\hline \multirow[t]{3}{*}{ Age at presentation } & $\leq 1$ month & $14(45.17 \%)$ \\
\hline & $>1$ month $-\leq 1$ year & $16(51.62 \%)$ \\
\hline & $>1$ year & $1(3.23 \%)$ \\
\hline
\end{tabular}

polymorphic variants (5T, 7T, 9T) in $15 / 25(60 \%)$ patients while $5 / 25$ (20\%) patients did not show any finding.

The detected mutations in this group included F508del mutation (exon 10) and W1282X mutation (exon 20) and they were found in $2(8 \%)$ patients each in addition to R1162X mutation (exon 19), which was found in 1 (4\%) patient only. All detected mutations 5/5 $(100 \%)$ were in the homozygous state and they all presented with typical combined respiratory and GI manifestations during the first year of life; $4 / 5$ (80\%) of them were products of consanguineous marriages, 1/5 (20\%) had a positive $P$. aeruginosa sputum culture, and all $5 / 5$ (100\%) patients suffered from failure to thrive.

The second group of patients enrolled in this study included 47 clinically suspected patients of CF, all residing in Basra City in the very south of Iraq; their ages ranged between (1 month and 15 years) years with a mean \pm SD of $2.74 \pm 3.19$ years. Of them, $30(63.8 \%)$ patients were males and $17(37.2 \%)$ were females with a M:F ratio of

Table 2 Clinical findings of 31 Iraqi CF patients

\begin{tabular}{ll}
\hline Clinical findings & No. (\%) \\
\hline Chronic cough & $28(90.3 \%)$ \\
Recurrent lower respiratory tract infections & $28(90.3 \%)$ \\
Greasy stool & $26(83.8 \%)$ \\
Palpable liver & $16(51.6 \%)$ \\
Chest wheezes and crepitations & $13(41.9 \%)$ \\
Abdominal distention & $5(16.1 \%)$ \\
Abdominal pain and vomiting & $1(3.2 \%)$ \\
Salty sweat & $1(3.2 \%)$ \\
\hline
\end{tabular}

1.76:1. The overall M:F ratio for both groups in this study was 1.6:1 [48 (66.7\%) males and 30 (33.3\%) females].

Molecular analysis of these patients showed that 9 (19.15\%) patients had 7 detectable mutations, all in homozygous states as follows: $3120+1 \mathrm{G}>\mathrm{A}$ in $3 / 47$ (6.38\%) patients, while I507del, W1282X, 2183AA $>$ G, R1162X, 3272-26A $>$ G, and R347P were detected in 1 (2.13\%) patient each. IVS8 polymorphic variants were also detected as follows: $7 \mathrm{~T} / 7 \mathrm{~T}$ in $25 / 47$ (53.2\%) patients, $7 \mathrm{~T} / 9 \mathrm{~T}$ in $8 / 47$ (17\%) patients, $9 \mathrm{~T} / 9 \mathrm{~T}$ in $4 / 47$ (8.5\%) patients, while $5 \mathrm{~T} / 7 \mathrm{~T}$ was seen in $1 / 47(2.13 \%)$ patient only.

Table 5 shows molecular data of both groups including all 72 molecularly tested Iraqi CF patients.

\section{Discussion}

The diagnosis of CF in Iraq is challenging due to physicians' low index of suspension. This disease was thought to be rare in this region and is similar in its presentation to other more common diseases in Iraq like tuberculosis, celiac disease, and immunodeficiency states. Lack of CF neonatal screening program and non-uniform availability of sweat chloride test or genotyping makes confirmation of clinical suspicions rely on clinical response to some available therapies like pancreatic enzyme supplementation, long-term course of the disease, and diagnosis by exclusion.

Interest in this disease has grown in the last decade as more patients are being discovered in Iraq, mostly in pediatric age groups. However, no published data or formal figures are available on the incidence and impact of CF in Iraq.

One unpublished study has been performed by Abbadi AF and Al-Janabi MK in 2016 that focused mainly on clinical characteristics and course of the disease of forty CF Iraqi children. A recently published study was conducted on $30 \mathrm{CF}$ Iraqi children and analyzed exon 10 and exon 17a of CFTR gene using Sanger sequencing without clinical correlation. They found 2 mutations and one polymorphic variant in $17 \mathrm{CF}$ patients, namely F508del in $5(16.6 \%)$ patients, and S466X in $1(3.3 \%)$ patient and M470V polymorphism in 11 (36.6\%) patients [8]; F508del was the only one tested for in the current study.

In this cross-sectional study, we described the demographic data, presentation, investigations, and complications of the clinically confirmed patients with CF. The overall M:F ratio of both groups was 1.6:1, which is nearly similar to that found in Bahrain, Saudi Arabia, Jordan, and Egypt with a M:F ratio of 1.37, 1.33, 1.32, and 1.5 respectively [9]. All patients enrolled in this study were children. 
Table 3 Basic investigations results of 31 Iraqi CF patients

\begin{tabular}{lll}
\hline Lab. Test & & No. (\%) \\
\hline Sweat chloride test & Range $=61-132 \mathrm{mmol} / \mathrm{L}$ & $31(100 \%)$ \\
Abnormal liver function tests & Mean $=97.13 \mathrm{mmol} / \mathrm{L}$ & $18(58.1 \%)$ \\
& Elevated ALT, AST, ALP & $13(41.9 \%)$ \\
& Increased total serum bilirubin & $12(38.7 \%)$ \\
Sputum culture & Low total serum protein & $\mathbf{6 ( 1 9 . 3 \% )}$ \\
& Pseudomonas aeruginosa & $2(6.5 \%)$ \\
& Klebsiella spp. & $15(48.4 \%)$ \\
Stool test for presence of fat & No growth & 8(25.8\%) \\
& Not performed & 26 (83.9\%) \\
\hline ALT & Positive (5+ fat droplet) & Negative (no fat) \\
\hline
\end{tabular}

ALT alanine aminotransferase, AST aspartate aminotransferase, ALP alkaline phosphatase

Parental consanguinity among 31 CF patients was $87.1 \%$. This is higher than the average consanguinity rates among Iraqi general populations (40-49\%) [10] but similar to the rates reported for other hereditary conditions in Iraq [11]. This finding also helps to explain the increasing occurrence of rare conditions such as CF and familial aggregation of patients which is seen in 5 (16.13\%) patients, similar to that reported in other regional countries [12, 13].

Almost all patients 30/31 (96.78\%) presented during the first year reflecting disease severity. This was nearly similar to a study from Egypt where $86 \%$ of patients presented during the first year of life [14].

Mutational analysis of all tested patients in this study $(n=72)$ showed that $3120+1 \mathrm{G}>\mathrm{A}$ and $\mathrm{W} 1282 \mathrm{X}$ were the most frequently detected mutations as seen in $3(4.17 \%)$ patients each. The former is known as the African CF mutation and has a frequency of $12.2 \%$ in African-

Table 4 Frequency of complications among 31 studied CF patients

\begin{tabular}{lll}
\hline Complications & No. & $\%$ \\
\hline Pneumonia & 27 & $87.1 \%$ \\
Growth failure & 20 & $64.5 \%$ \\
Hypertrophic osteoarthropathy (finger clubbing) & 17 & $54.8 \%$ \\
Meconium ileus & 12 & $38.7 \%$ \\
Bronchiectasis & 5 & $16.1 \%$ \\
Death & 4 & $12.9 \%$ \\
Distal Intestinal obstruction syndrome & 3 & $9.7 \%$ \\
Hepatic steatosis & 1 & $3.2 \%$ \\
Chronic pancreatitis & 1 & $3.2 \%$ \\
Nasal polyp(s) & 1 & $3.2 \%$ \\
Aspergillosis & 1 & $3.2 \%$ \\
\hline
\end{tabular}

American people [15] and was reported in an Iranian study with a similar frequency as ours [16]. The other mutation, W1282X, was reported as the most common mutation in patients from Arab ethnic backgrounds [17] and has a similar frequency to an Egyptian study [12]. This result was different from what was detected in a recently published Iraqi study which revealed that F508del mutation was the most commonly encountered mutation in a sample of 30 Iraqi CF patients as seen in 5 (16.6\%) patients [8]. This mutation was the second most common mutation detected in the current study along with $\mathrm{R} 1162 \mathrm{X}$ with a frequency of $2.78 \%$ as detected in 2 patients each.

F508del is considered the most common CFTR mutation in other Arab countries like Lebanon (34\%) [18] and Egypt (58\%) [12], while R1162X has only been reported in Egypt in 3 patients (6\%) [12] but was the second-ranking mutation in the previously published Iraqi study, where $5(16.6 \%)$ patients had this mutation [8]. For these reasons, this mutation needs to be included in all future tests.

The other 4 mutations detected in this study were seen in one patient only with a frequency of $1.38 \%$ each and included (3272-26A $>$ G, R347P, I507del, and 2183AA $>$ G).

3272-26A $>$ G mutation, which creates an alternative acceptor splice site in intron $17 \mathrm{a}$, is considered the second most common mutation after F508del in the Belgian CF population with a frequency of $3.8 \%$ [19]. Al-Abadi et al study showed this mutation in one Jordanian patient [20].

Searching published reports from the Arab world showed that R347P mutation was only reported in Egypt in $2 \%$ of patients [12] along with the current study. The worldwide frequency of $\mathrm{R} 347 \mathrm{P}$ mutation is about $0.2 \%$ and it is mostly found in the south of Bulgaria [21]. 
Table 5 CFTR gene mutations/variant detected in 72 molecularly tested CF Iraqi patients

\begin{tabular}{|c|c|c|c|c|c|c|}
\hline Genotype & Mutation Class & Position & Nucleotide variation & Protein change & Zygosity & No.(\%) of cases \\
\hline \multicolumn{7}{|l|}{ Mutations } \\
\hline $3120+1 G>A^{a}$ & Class I & Intron 16 & c. $2988+1 G>A$ & - & homozygous & $3(4.17 \%)$ \\
\hline$W 1282 X^{b}$ & Class 1 & Exon 20 & c. $3846 \mathrm{G}>\mathrm{A}$ & p.Trp1282X & Homozygous & $3(4.17 \%)$ \\
\hline F508del $^{c}$ & Class ॥ & Exon 10 & c.1521_1523delCTT & p.Phe508del & Homozygous & $2(2.78 \%)$ \\
\hline$R 1162 X^{b}$ & Class IV & Exon 19 & c. $3484 C>T$ & p.Arg1162X & Homozygous & $2(2.78 \%)$ \\
\hline $3272-26 A>G$ & Class V & Intron 17 & c. $3140-26 \mathrm{~A}>\mathrm{G}$ & - & Homozygous & $1(1.38 \%)$ \\
\hline R347P & Class IV & Exon 7 & c. $1040 G>C$ & p.Arg347Pro & Homozygous & $1(1.38 \%)$ \\
\hline 1507del & Class II & Exon10 & c.1519_1521delATC & p.lle507del & Homozygous & $1(1.38 \%)$ \\
\hline $2183 A A>G$ & Class I & Exon 13 & c.20512052delAAinsG & p.Lys684SerfsX38 & Homozygous & $1(1.38 \%)$ \\
\hline \multicolumn{6}{|c|}{ Total cases with detected mutations } & $14 / 72(19.44 \%)$ \\
\hline \multicolumn{7}{|c|}{ c.1210-12T[n] background } \\
\hline IVS8 7T/7T & - & Intron 8 & c.1210-12 T[7] & - & Homozygous & $36(50 \%)$ \\
\hline IVS8 7T/9T & - & Intron 8 & c.1210-12 T[7] /[9] & - & Heterozygous & $10(13.9 \%)$ \\
\hline IVS8 9T/9T & - & Intron 8 & c.1210-12 T[9] & - & Homozygous & $5(6.94 \%)$ \\
\hline IVS8 5T/7T & - & Intron 8 & c.1210-12 T[5] /[7] & - & Heterozygous & $2(2.78 \%)$ \\
\hline \multicolumn{6}{|c|}{ Total cases with detected polymorphic variants } & $53 / 72(73.62 \%)$ \\
\hline \multicolumn{6}{|l|}{ Unidentified } & $5(6.94 \%)$ \\
\hline
\end{tabular}

${ }^{a}$ All 3 cases had additional 7T/7T variant

${ }^{\mathrm{b}}$ One case had an additional 7T/7T variant

'2 cases had additional 9T/9T variant

I507del mutation is only reported in this study but not in other regional countries, while $2183 \mathrm{AA}>\mathrm{G}$ was detected in Jordan (6\%) [20], Iran (7\%) [13], Turkey (2.5$4.9 \%$ ) [22], and the Northeast of Italy (9.3\%) [23].

All patients with detected mutations from the first group $(n=5)$ presented during the first year which is the usual age of presentation of CF patients [24]; all had abnormally high levels of sweat chloride values and failure to thrive which may necessitate aggressive management to slow the progress and reduce potential complications. One patient in this study had R1162X mutation and presented with milder pulmonary manifestations. This mutation results in a protein with a residual regulatory region that may be partially functioning in the lung tissues [25].

Over the years, the IVS8 c.1210-12T[5_9] (polypyrimidine tract in intron 8) and adjacent c.1210-35_121012GT[8_13] (TG repeat tracts) in the CFTR gene have received much more attention due to their potential roles in the development of male infertility. The polymorphic IVS8 c.1210-12T[5_9] consists of three common variants, namely $5 \mathrm{~T}, 7 \mathrm{~T}$, and $9 \mathrm{~T}$, and this locus functions as the acceptor site of alternative splicing of CFTR exon 9 [26].

The presence of some polymorphic variants is not by itself pathogenic, but some variants are associated with the presence of certain splice mutations. The shortest $(5 \mathrm{~T})$ is associated with the highest rate of incomplete transcripts. mRNA without exon 9 results in immature CFTR proteins with improper function [27].

The 7T allele can be found in normal individuals with a relative frequency of $80 \%$ in Caucasians [28] and $90 \%$ in East Asians [29]. In the current study, IVS8 7T/7T variant was detected in $50 \%$ of patients which was nearly similar to what was reported in a study from Iran (60\%); IVS8 7T/9T and 5T/7T heterozygous states were detected in $16.7 \%$ in this study but in $30 \%$ in the same study from Iran [30]; the same applies to $9 \mathrm{~T} / 9 \mathrm{~T}$ variant, which was detected in $6.94 \%$ in the current study but more in the Iranian study (10\%) [30]. This particular variant was also encountered in association with F508del mutation in two patients, unlike the Lebanese study that showed $66.7 \%$ of the F508del was associated with 7T allele [31].

Some mutations detected in this study were not associated with any of the tested c.1210-12T[5T/7T/9T] variants in the used kit. The presence of mutations without a detected variant is expected as other variants have not been tested, which may suggest that some specific Iraqi combinations may exist and be associated with novel pathogenic variants in the same allele.

Differences in allele frequencies and clinical presentation could be related to the considerable heterogeneity in CFTR mutations, a variation of these mutations in different populations, in addition to the interaction of genetic and environmental factors [19]. 
All detected mutations have a high genotype/phenotype correlation as all patients express typical and moderate-severe clinical presentation and disease course.

Based on these findings, the currently used kit can diagnose about $20 \%$ of patients; the remaining $80 \%$ require further testing for large rearrangements with quantitative methods. Such methods could include multiplex ligation-dependent probe amplification (MLPA) or nextgeneration sequencing (NGS) with an adapted algorithm and specific sequencing of well-known deep intronic variants. These tests could be the next step to complete the CFTR gene analysis of molecularly undiagnosed patients. They may reveal probable novel mutations as Iraq, especially the central parts, is well known to harbor heterogeneous mutations from all over the world [32] as it was once the center of attention in education and trade.

\section{Conclusions}

$\mathrm{CF}$ is not rare in Iraq as previously thought. Diagnosis remains problematic in some patients. A lengthy multistep molecular diagnostic strategy is still recommended till we build a database that enables shorter and less expensive testing. Synthesis of a custom-made panel for the most commonly encountered mutations can be used for CFTR mutation detection in this region of the world. More studies on a larger number of CF patients are necessary to determine the incidence and molecular data of CF in Iraq. This can help assist in rapid detection and solve diagnostic hardships as well as it aids in the nearly forgotten prenatal diagnosis.

\section{Abbreviations}

ALP: Alkaline phosphatase; ALT: Alanine aminotransferase; AST: Aspartate aminotransferase; CF: Cystic fibrosis; CFTR: Cystic fibrosis transmembrane conductance regulator; M:F ratio: Male to female ratio; MIM: Mendelian Inheritance In Man; MLPA: Multiplex ligation-dependent probe amplification; NGS: Next-generation sequencing

\section{Acknowledgements}

Not applicable.

\begin{abstract}
Authors' contributions
AGAQ contributed to collection of data of the first group, performed molecular analysis for them, data analysis, and drafting of the manuscript. BMAM contributed to the concept and design of the study, data analysis, drafting, and finalization of the manuscript; RFT contributed to patient recruitment, clinical assessment, and diagnosis of enrolled cases in first group; SAB performed the genetic analysis to the second group. All authors have read and approved the manuscript.
\end{abstract}

\section{Funding}

No fund has been granted to this work.

\section{Declarations}

\section{Ethics approval and consent to participate}

This study was approved by the Research Ethics Committee of Dept. of Pathology, \& Forensic Medicine, College of Medicine, University of Baghdad (document \#1356 in October $23^{\text {th }}, 2019$ ) as well as from the Ethical Committee of the Ministry of Health, Baghdad, Iraq (document \#45961 in November 25th, 2019).

All patients' parents have given their verbal consent to participate in this study as patients' personal data remain anonymous. The patients' parents agreed to participate when informed that the obtained results of this study would probably detect their child's mutation and the test would be free of charge and improve their chances to have a prenatal diagnosis later on if they got a positive result of mutation detection and would help other patients with this disease by improving molecular diagnosis in Iraq. Both Research Ethics Committees approved these above mentioned steps. All authors revised and approved the final submitted version of the manuscript for publication.

We confirm that this work is original and has not been published elsewhere, nor is it currently under consideration for publication elsewhere.

\section{Consent for publication}

Not applicable.

\section{Competing interests}

All authors declare that there is no conflict of interest to disclose.

\section{Author details}

'Department of Medical Genetics, Kamal Alsamaraey Hospital (Infertility Center), Ministry of Health, Baghdad, Iraq. ${ }^{2}$ Department of Pathology and Forensic Medicine, College of Medicine, University of Baghdad, Baghdad, Iraq. ${ }^{3}$ Children Welfare Hospital, Medical City, Baghdad, Iraq. ${ }^{4}$ Department of Pediatrics, College of Medicine, University of Baghdad, Baghdad, Iraq. ${ }^{5}$ Department of Pathology and Forensic Medicine, College of Medicine, University of Basra, Basra, Iraq.

Received: 28 January 2021 Accepted: 31 March 2021

Published online: 11 May 2021

\section{References}

1. Egan ME, Green DM, Voynow JA (2019) Cystic fibrosis. In: Kligman RM, Stanton BF, ST Geme JW III, Schor NF (eds) Nelson Textbook of Pediatrics, vol 2. Elsevier Inc, pp 2098-2113

2. Kambouris M, Banjar H, Moggari I, Nazer H, Al-Hamed M, Meyer BF (2000) Identification of novel mutations in Arabs with cystic fibrosis and their impact on the cystic fibrosis transmembrane regulator mutation detection rate in Arab populations. Eur J Pediatr 159(5):303-309

3. Al-Ghamdi SA (2017) Cystic fibrosis and consanguinity in the Saudi Arabian population. Nat Sci 15(5):6-10

4. Cystic fibrosis mutation database. 2021. http://www.genet.sickkids.on.ca/Sta tisticsPage.html. Accessed 2 Mar 2021.

5. De Boeck K, Zolin A, Cuppens H, Olesen HV, Viviani L (2014) The relative frequency of CFTR mutation classes in European patients with cystic fibrosis. J Cyst Fibros 13(4):403-409

6. Banjar H (1999) Overview of cystic fibrosis: patients aged 1-12 years in a tertiary care center in Saudi Arabia. Middle East Pediatr 4(2):44-49

7. Dequeker E, Stuhrmann M, Morris MA, Casals T, Castellani C, Claustres M et al (2009) Best practice guidelines for molecular genetic diagnosis of cystic fibrosis and CFTR-related disorders--updated European recommendations. Eur J Hum Genet 17(1):51-65

8. Zaidan A, Salman J, Arif H (2020) The spectrum of mutations analysis of exons 10 and 17a of CFTR gene in Iraqi patients with cystic fibrosis disease. Biochem Cell Arch 20(2):6177-6181

9. Al-Sadeq D, Abunada T, Dalloul R, Fahad S, Taleb S, Aljassim K et al (2019) Spectrum of mutations of cystic fibrosis in the 22 Arab countries: A systematic review. Respirology. 24(2):127-136

10. Hamamy H (2012 Jul) Consanguineous marriages: preconception consultation in primary health care settings. J Commun Genet 3(3):185-192

11. Al-Rahal NK (2018 Oct 1) Inherited bleeding disorders in iraq and consanguineous marriage. Int J Hematol Oncol Stem Cell Res 12(4):273-281 
12. Shahin WA, Mehaney DA, El-Falaki MM (2016) Mutation spectrum of Egyptian children with cystic fibrosis. Springerplus. 5(1):686

13. Reisi M, Behnam M, Sayedi S, Salimi F, Kargar P, Salehi M et al (2019) Prevalence of cystic fibrosis trans-membrane conductance regulator gene common mutations in children with cystic fibrosis in Isfahan, Iran. Int J Pediatr 7(4):9333-9339

14. El-Falaki MM, Shahin WA, El-Basha NR, Ali AA, Mehaney DA, El-Attar MM (2014 Sep) Profile of cystic fibrosis in a single referral center in Egypt. J Adv Res 5(5):563-568

15. Macek M Jr, Mackova A, Hamosh A, Hilman BC, Selden RF, Lucotte G et al (1997) Identification of common cystic fibrosis mutations in AfricanAmericans with cystic fibrosis increases the detection rate to $75 \%$. Am J Hum Genet 60(5):1122-1127

16. Alibakhshi R, Kianishirazi R, Cassiman JJ, Zamani M, Cuppens H (2008 Mar) Analysis of the CFTR gene in Iranian cystic fibrosis patients: identification of eight novel mutations. J Cyst Fibros 7(2):102-109

17. Laufer-Cahana A, Lerer I, Sagi M, Rachmilewitz-Minei T, Zamir C, Rivlin JR et al (1999) Cystic fibrosis mutations in Israeli Arab patients. Hum Mutat 14(6): 543

18. arra C, Menassa R, Awwad J, Morel Y, Salameh P, Yazbeck N, et al. (2010) Mutational spectrum of cystic fibrosis in the Lebanese population. J Cyst Fibros 9(6):406-410

19. Storm K, Moens E, Vits L, Vlieger HD et al (2007) High incidence of the CFTR mutations 3272-26A $\rightarrow \mathrm{G}$ and L927P in Belgian cystic fibrosis patients, and identification of three new CFTR mutations (186-2A $\rightarrow \mathrm{G}, \mathrm{E} 588 \mathrm{~V}$, and 1671insTATCA). J Cyst Fibros 6(6):371-375

20. Al-Abadi B, Al-Hiary M, Khasawneh R, Al-Momani A, Bani-Salameh A, AlSaeidat $S$ et al (2019) Cystic fibrosis gene mutation frequency among a group of suspected children in king hussein medical center, REVIEW. Med Arch 73(2):118-120

21. Estivill X, Bancells C, Ramos C (1997) Geographic distribution and regional origin of 272 cystic fibrosis mutations in European populations. The biomed CF mutation analysis consortium. Hum Mutat 10(2):135-154

22. Kýlýnc MO, Ninis VN, Dag E, Demirko M, Ozkýnay F, Arýkan Z et al (2002) Highest heterogeneity for cystic fibrosis: 36 mutations account for $75 \%$ of all CF chromosomes in Turkish patients. Am J Hum Genet 113:250-257

23. Castellani C, Gomez Lira M, Frulloni L, Delmarco A, Marzari M, Bonizzato A et al (2001) Analysis of the entire coding region of the cystic fibrosis transmembrane regulator gene in idiopathic pancreatitis. Hum Mutat 18(2): 166

24. Jackson A, Foley L, Daly L, Fitzpatrick P, Harrington M, Zhou S et al (2010) Delayed cystic fibrosis presentation in children in the absence of newborn screening. Ir Med J 103(4):113-116

25. Gasparini P, Borgo G, Mastella G, Bonizzato A, Dognini M, Pignatti PF (1992) Nine cystic fibrosis patients homozygous for the CFTR nonsense mutation R1162X have mild or moderate lung disease. J Med Genet 29(8):558-562

26. Jianmin Y, Kevin C, Tao Z, Zhiling L, Ya N, Zhongxiang N (2011) Association of genetic variants in CFTR gene, IVS8 C.1210-12T[5_9] and C.1210-35_121012GT[8_12], with spermatogenetic failure: Case-control study and metaanalysis. Mol Hum Reprod 17(9):594-603

27. Chillon M, Casals T, Mercier B, Bassas L, Lissens W, Silber S, Romey MC, RuizRomero J, Verlingue C, Claustres M et al (1995) Mutations in the cystic fibrosis gene in patients with congenital absence of the vas deferens. $\mathrm{N}$ Engl J Med 332(22):1475-1480

28. Grangeia A, Niel F, Carvalho F et al (2004) Characterization of cystic fibrosis conductance transmembrane regulator gene mutations and IVS8 poly(T) variants in Portuguese patients with congenital absence of the vas deferens. Hum Reprod 19:2502-2508

29. Huang Q, Ding W, Wei MX (2008) Comparative analysis of common CFTR polymorphisms poly-T, TG-repeats and M470Vin a healthy Chinese population. World J Gastroenterol 14:1925-1930

30. Tabaripoura R, Niakib HA, Doukic MR et al (2012) Poly thymidine polymorphism and cystic fibrosis in a non-Caucasian population. Dis Markers 32:241-246

31. Desgeorges M, Mégarbané A, Guittard C et al (1997) Cystic fibrosis in Lebanon: distribution of CFTR mutations among Arab communities. Hum Genet 100:279-283

32. Al-Musawi BMS, Al-Allawi N, Abdul-Majeed BA, Eissa AA, Jubrael JMS, Hamamy H (2012) Molecular characterization of glucose-6-phosphate dehydrogenase deficient variants in Baghdad city - Iraq. BMC Blood Disord 12(1):4

\section{Publisher's Note}

Springer Nature remains neutral with regard to jurisdictional claims in published maps and institutional affiliations.

\section{Submit your manuscript to a SpringerOpen ${ }^{\circ}$ journal and benefit from:}

- Convenient online submission

- Rigorous peer review

- Open access: articles freely available online

High visibility within the field

- Retaining the copyright to your article

Submit your next manuscript at $\boldsymbol{\nabla}$ springeropen.com 